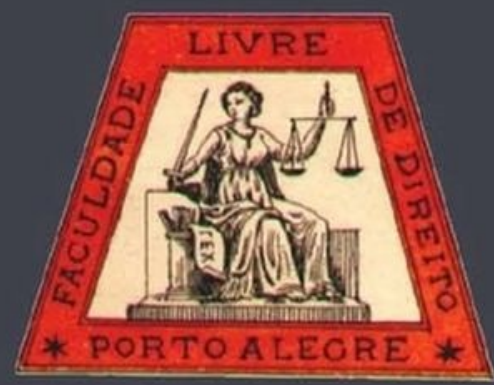

\title{
A teoria do direito natural no tempo pós-moderno
}

\author{
Natural Law theory in post-modern times
}

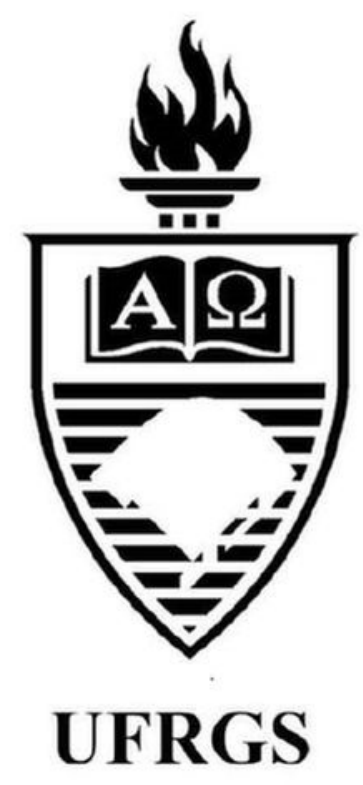

Carlos I. Massini Correas

Universidade de Mendoza 


\title{
A teoria do direito natural no tempo pós-moderno ${ }^{* * *}$
}

\author{
Natural Law theory in post-modern times
}

Carlos I. Massini Correas ${ }^{* * *}$

\section{REFERÊNCIA}

CORREAS, Carlos I. Massini. A teoria do direito natural no tempo pós-moderno. Tradução de Frederico Bonaldo. Revista da Faculdade de Direito da UFRGS, Porto Alegre, n. 39, vol. esp., p. 25-39, dez. 2018.

\section{RESUMO}

Assim como em quase todas as matérias, é conveniente fazermos um pouco de história para compreendermos a situação atual da teoria do direito. No caso deste trabalho, vamos remontar apenas até a Idade moderna, pois, como bem diz Daniel Innerarity, "a filosofia contemporânea transformou-se numa reflexão sobre a modernidade". Esquematizando muito, por razões elementares de brevidade, podemos afirmar que é possível diferenciar três traços centrais na filosofia moderna: a) perda da noção teleológica de natureza; b) aparição da concepção moderna do sujeito; c) imanentização do pensamento.

\section{PALAVRAS-CHAVE}

Direito Natural. Pós-modernidade. Filosofia contemporânea. Jusnaturalismo.

\section{ABSTRACT}

As in almost all disciplines, it is convenient to study a bit of history in order to understand the current status of legal theory. In the case of this paper, we will remount only until Modern Age, for, as says correctly Daniel Innerarity, "contemporary philosophy has turned itself into a reflection on modernity". Outlining considerably, for elementary reasons of brevity, we can affirm that it is possible to discriminate three central features in modern philosophy: a) the loss of the theological notion of nature; b) the emergence of the modern conception of the subject; c) the immanentization of thought.

\section{KEYWORDS}

Natural Law. Post-modernity. Contemporary philosophy. Natural Law theory.

\section{SUMÁRIO}

Introdução. 1. As notas da modernidade. 2. A modernidade ético-jurídica. 3. A crítica pós-moderna. 4. As tentativas de refundamentação (I): o neo-Iluminismo. 5. As tentativas de refundamentação (II): o neojusnaturalismo. Conclusões. Bibliografia.

\section{INTRODUÇÃO}

Motivados por um dos subtemas do presente congresso Justiça e Direito Natural, dedicado à apresentação e discussão da problemática do direito natural a partir da perspectiva da filosofia do direito, vamos abordar sinteticamente o tema das possibilidades do jusnaturalismo nos tempos pós-modernos e, em especial, o tema da tarefa da teoria do direito natural nesse contexto. Em outras palavras, aqui se procurará dar uma resposta a estas perguntas: (1) em que situação ficou a teoria do direito depois do colapso do paradigma jurídico moderno e após terem aparecido os chamados pósmodernismos, que ensaiaram a aplicação de novos paradigmas ao direito? (2) Frente a essa situação, a teoria - ou teorias - do direito natural tem alguma tarefa relevante a cumprir? (3) Em caso afirmativo, em que consiste

\footnotetext{
* Artigo originalmente intitulado "La teoría del derecho natural en el tiempo posmoderno", publicado em Doxa, Alicante (Espanha), 1998, vol. II, n. 21, p. 289-303. Tradução para o português por Frederico Bonaldo (Universidade Católica de Santos).

** Devo agradecer aqui expressamente a Miguel Verstraete, a Ricardo Crespo, a Daniel Gamarra e a Jorge Martínez Barrera, que leram o original deste trabalho e sugeriram-me correções valiosas e oportunas.

*** Catedrático emérito de Filosofia do Direito da Universidade de Mendoza, Argentina.
} 
fundamentalmente essa nova tarefa do jusnaturalismo nos tempos pós-modernos?

\section{AS NOTAS DA MODERNIDADE}

Assim como em quase todas as matérias, é conveniente fazermos um pouco de história para compreendermos a situação atual da teoria do direito. No caso deste trabalho, vamos remontar apenas até a Idade moderna, pois, como bem diz Daniel Innerarity, "a filosofia contemporânea transformou-se numa reflexão sobre a modernidade" 1 . Esquematizando muito, por razões elementares de brevidade, podemos afirmar que é possível diferenciar três traços centrais na filosofia moderna, em torno dos quais giram as ideias e ideais dessa etapa do pensamento; esboçados esquematicamente, esses traços são os seguintes:

a) Perda da noção teleológica de natureza: neste sentido, a noção clássica do mundo como natureza dotada de um sentido intrínseco entrou em crise fundamentalmente a partir da captação excludente da realidade por parte das ciências naturais modernas, que, por um lado, a conceberam como uma mera matéria passível de objetivação, mensurável e quantificável, e, por outro, como o objeto de um domínio progressivo e manipulador por parte do homem:

Com o nascimento da ciência moderna, produziu-se o abandono da teleologia. Esse abandono não foi forçado pelo fenômeno; por trás dele, escondia-se um interesse poderoso. $\mathrm{O}$ fenômeno até mesmo se opõe a uma interpretação não teleológica. Por isto, força um equivalente provisório. Um desses equivalentes é a doutrina dos dois mundos, em suas diferentes formas: reino das causas e reino dos fins, ser e dever, fatos e valores. A própria teoria dos valores é um desses equivalentes. Fatos desprovidos de valor e reino de valores oposto a esses fatos são o

\footnotetext{
1 INNERARITY, Daniel. Dialéctica de la modernidad. Madrid: Rialp, 1990. p. 12. Veja-se também LLANO, Alejandro. Claves filosóficas del actual debate cultural. Humanitas, Santiago de Chile, 1996, n. 4, p. 532-544.

${ }^{2}$ SPAEMANN, Robert. La actualidad del derecho natural. In: SPAEMANN. Crítica de las utopías políticas.
}

produto da desintegração da enteléquia [a natureza como fim] precedente ${ }^{2}$.

Essa desintegração da natureza como enteléquia não foi senão uma parte coerente do processo que Max Weber chamou de "desencantamento do mundo", pelo qual este passou de ser um cosmos ordenado em si mesmo a desempenhar o papel de uma mera res extensa ou matéria, somente apta para os cálculos e medições de um conhecimento deliberadamente reduzido a ciência físico-matemática e intrinsecamente ordenado à sua ulterior utilização técnica. Evidentemente, do mundo assim concebido, não se pode extrair diretiva alguma para a conduta humana, a qual fica à mercê da autonomia da razão, entendida como construtora dos seus próprios objetos. Portanto, entrou em crise a noção clássica de lei natural, no sentido de uma normatividade do agir humano que podia ser descoberta nas suas linhas gerais por meio de uma interpretação da realidade natural ${ }^{3}$.

b) Aparição da concepção moderna do sujeito: na Idade moderna, esse mundo mudo e sem sentido foi submetido a um sujeito configurador dos seus objetos de conhecimento e de vontade. Para este sujeito, "conhecer é poder" (Francis Bacon); e ele vai à busca de uma ciência que o torne "dono e senhor da natureza" (Descartes). Sobre isto, escreveu Gómez Robledo:

Com efeito, num mundo que se reduziu a matéria e a
movimento, as relações físico-matemáticas, com
cujo conhecimento o homem pode - dentro de certos
limites - agir e dominá-lo, a ação tem um valor
incomparavelmente maior que a contemplação.
Tem-no porque o homem, por sua vez, possui uma
dignidade muito maior que esse mundo; e a quem é
superior cabe agir sobre aquilo que é inferior, ao

Pamplona: EUNSA, 1980. p. 324-325. Sobre as ideias de Spaemann a este respeito, veja-se GONZÁLEZ, Ana Marta. Naturaleza y dignidad: un estudio desde Robert Spaemann. Pamplona: EUNSA, 1996.

${ }^{3}$ Cf. VILLEY, Michel. La formation de la pensée juridique moderne. Paris: Montchrestien, 1968. 
invés de limitar-se a adotar a atitude passiva do espectador ${ }^{4}$.

Assim, esse sujeito é o doador do sentido da realidade através de uma função construtiva - e não mais contemplativa - da consciência raciocinadora e da vontade. E essa consciência pode ser apenas construtiva, porque, ao ter deixado de ser receptiva, só pode obter os seus conteúdos mediante um processo metodicamente controlado de elaboração ou construção. Consequentemente, tudo o que existe só ganha sentido em referência ao sujeito - especialmente os conteúdos da ética, seja pessoal ou social.

c) Imanentização do pensamento: pensamento centrado no sujeito tende a transformar-se progressivamente em imanente, tanto no sentido da imanência metafísica negação de tudo o que transcenda o mundo como da imanência noética - negação de tudo o que não esteja contido na consciência. Rafael Alvira escreveu com grande precisão que "a meu ver, é a negação explícita ou implícita da transcendência e a aparição da primazia da consciência o que caracteriza essa modernidade par excellence" 5. Como consequência dessa negação, o pensamento moderno "emancipa-se" de toda sujeição possível, quer seja "por cima”, ao libertar-se do controle da revelação e da teologia, quer seja "por baixo", ao libertar-se dos limites inevitáveis postos pelas estruturas da realidade ao pensamento contemplativo e receptivo. Esse movimento em direção a uma imanência cada vez

\footnotetext{
${ }^{4}$ GÓMEZ ROBLEDO, Antonio. Ensayo sobre las virtudes intelectuales. México: Fondo de Cultura Económica, 1986. p. 145. Veja-se também GÓMEZ ROBLEDO. L'etica teologica e le istanze della posmodernità. In: AA.VV. Prospettive etiche nella posmodernità. Milano: San Paolo, 1994. p. 54 et seq.

5 ALVIRA, Rafael. Reivindicación de la voluntad. Pamplona: EUNSA, 1988. p. 228.

${ }^{6}$ Cf. FAZIO, Mariano; GAMARRA, Daniel. Introduzione alla storia della filosofia moderna. Roma: Apollinare Studi, 1994.

${ }^{7}$ TOMÁS DE AQUINO. Suma de teologia, I-II, q. 91, a. 2.

8 Cf. MASSINI CORREAS, Carlos Ignacio. La desintegración del pensar jurídico clásico en Edad Moderna.
}

maior explica a passagem, no campo das ideias e das vivências religiosas, do teísmo ao deísmo, e, por fim, ao ateísmo ${ }^{6}$. É óbvio que, dentro deste esquema, a noção tomista de lei natural como "participação da lei eterna na criatura racional" 7 é absolutamente impensável. Consequentemente, o direito natural moderno centrou os seus esforços na construção racional de um sistema jurídico completo e metodicamente rigoroso ${ }^{8}$.

\section{A MODERNIDADE ÉTICO-JURÍDICA}

Se agora transladamos estas notas da modernidade ao âmbito do direito, elas transformam-se igualmente em características do pensamento jurídico moderno. Expostas sucintamente, elas são as seguintes:

a) Perda da noção clássica de lei natural: com o desaparecimento da concepção clássica de natureza-enteléquia, capaz de ser fonte de sentido jurídico e raiz de conteúdos normativos com relativa independência do sujeito pensante, esse sentido e essa raiz passam a situar-se necessariamente nesse sujeito, que fabrica normas e princípios práticos a partir de postulados da sua própria razão:

\begin{abstract}
Com a exceção parcial de Grócio, esses escritores modernos [Hobbes, Pufendorf, Locke etc.] sustentavam que não há qualquer significado moral ou político inerente na estrutura das coisas. Todo significado ou valor é querido ou construído e imposto sobre um mundo natural que, em si mesmo, é amoral e apolítico ${ }^{9}$.
\end{abstract}

Buenos Aires: Abeledo Perrot, 1980. Todas estas notas adquiriram a sua formulação paradigmática no pensamento de Immanuel Kant: "Kant expressa o mundo moderno num edifício de ideias" (HABERMAS, Jürgen. El discurso filosófico de la modernidad. Buenos Aires: Taurus, 1989, p. 32). Tanto foi assim, que a maioria das tentativas contemporâneas de reivindicar e revalorizar o pensamento da modernidade remetem-se ao próprio Kant (cf. ROSEN, Allen D. Kant's theory of justice. Ithaca - London: Cornell University Press, 1993).

${ }^{9}$ HAAKONSEN, Knud. Natural law and moral philosophy: from Grotius to the Scottish enlightenment. New York: Cambridge University Press, 1996. p. 102. 
Este modo de pensar é especialmente posto em evidência nas ideias de David Hume, para quem as noções de justiça, propriedade, direito etc. são meramente artificiais, criações voluntárias do homem por razões de utilidade comum ${ }^{10}$. Nesta perspectiva, o espaço antes ocupado pela lei natural foi preenchido por um "direito racional" construído pelo sujeito de modo dedutivo a partir de postulados da sua própria razão; é esta e não outra a fonte dos sistemas modernos de "direito natural" que precederam a codificação, o constitucionalismo racionalnormativo e o "sistemismo jurídico" do século XX.

b) Aparição da noção moderna de direitos humanos: em conformidade com a exaltação de um sujeito doador de sentido e dotado de uma autonomia "forte" ou absoluta, surgiu a noção moderna de direitos humanos, que os concebeu como prerrogativas inerentes ao sujeito, prévias à sua vida social e sem fundamento transcendente algum. Nesta perspectiva, a única justificação racional que pode ser dada aos direitos humanos radica na "santidade" (Kant) que cabe à pessoa humana graças à sua autonomia e à sua racionalidade:

A modernidade das declarações de direitos do homem do final do século XVIII está necessariamente vinculada à filosofia da consciência e à teoria do sujeito. Mais ainda, elas são o testemunho de um acontecimento irreversível na história da filosofia: a transformação da ideia de natureza e o advento do sujeito ${ }^{11}$.

\section{c) Fundamentação imanente do direito: por} fim, outra coisa muda na Idade moderna: a fundamentação das leis e dos direitos passou a não mais radicar na lei eterna de Deus nem na lei natural descoberta a partir das estruturas das coisas, mas, pura e simplesmente, na razão do sujeito construtor - o "direito natural moderno" ou nos simples mandatos do soberano - o imperativismo de Hobbes a Kelsen, passando por Bentham e Austin ${ }^{12}$. Em todos os casos, sempre é o sujeito humano quem dá origem integral às normas da convivência, quer porque constrói um sistema jurídico racional, quer porque institui - a modo de um artifício - a autoridade que impera as normas. E é nessa ruptura normativa da modernidade com a transcendência ontológica e noética que se encontra a raiz autêntica do positivismo jurídico. E, do ponto de vista epistemológico, isto só se fez possível a partir da mais completa imanentização dos fundamentos das ordens jurídica e moral ${ }^{13}$.

\section{A CRÍTICA PÓS-MODERNA}

A concepção moderna do direito que sintetizamos e esquematizamos no ponto precedente foi a corrente central da teoria do direito até bem avançado o século XX. Decerto, ela foi objeto de embates persistentes por parte dos defensores da concepção clássica do direito, mas esses ataques não conseguiram pôr em perigo o seu reinado, que, com altos e baixos, se manteve praticamente até a década de 1970. A partir de então, surgiu uma nova corrente de ideias no cenário político do ocidente; ela centrou-se numa crítica integral do projeto moderno, recorrendo a Marx, Nietzsche, Freud e Heidegger como os seus principais mentores. Dentro dessa corrente - que

se outra coisa: a ordem da natureza humana como arte, fabricação, convenção, intelecção" (p. 53).

12 Sobre estes autores, veja-se KELLY, John M. A short history of Western legal theory. Oxford: Clarendon Press, 1994. p. 301 et seq.

13 Cf. CARPINTERO, Francisco. Los inicios del positivismo jurídico en Centro Europa. Madrid: Actas, 1992; GOYARD-FABRE, Simone. Les fondements de l'ordre juridique. Paris: PUF, 1992. p. 95 et seq. 
reivindica para si o monopólio do pensamento pós-moderno e cujos principais representantes associam-se ao pós-estruturalismo francês também se realizaram tentativas de criticar integralmente a concepção moderna do direito e da ética em geral ${ }^{14}$. Vamos expor sucintamente as linhas principais dessa crítica pós-moderna, de modo a permitir depois o estudo das tentativas de saída do ponto morto a que chega essa crítica absoluta, meramente negativa e sem solução ${ }^{15}$. Essas linhas críticas, coincidentes com as que analisamos ao estudar a modernidade, são as seguintes:

a) Crítica da razão construtiva $e$ sistemática: um dos principais pontos da crítica pós-moderna ao pensamento da modernidade radica na negação das possibilidades sistematizadoras e construtivas da realidade que foram atribuídas à razão:

O contexto atual da filosofia é definido pela crítica do paradigma moderno de uma razão totalizadora [...]. Para Lyotard, a ruptura com a razão totalizadora implica o abandono dos grandes récits [grandes relatos], isto é, das grandes narrações, do discurso com pretensões de universalidade, e o retorno das petites histoires [pequenas histórias] [...]. Perdeu credibilidade a ideia de um discurso, de um consenso, de uma história ou de um progresso no singular; no lugar deles, aparece uma pluralidade de âmbitos de discurso e narrações ${ }^{16}$.

$\mathrm{Na}$ perspectiva pós-moderna, a razão construtiva, sistemática e universalista da modernidade, atacada como "torturadora" e "encobridora" da realidade, é substituída por uma “arqueologia do saber" (Foucault), que, por fim, desemboca num irracionalismo anárquico, descontextualizado e anônimo.

\footnotetext{
${ }^{14}$ Sobre essas tentativas, veja-se RENAUT, Alain; SOSOE, Lukas. Philosophie du droit. Paris: PUF, 1993. p. 41-68.

${ }^{15}$ Cf. BALLESTEROS, Jesús. Posmodernidad: decadencia o resistencia. Madrid: Tecnos, 1989.

${ }^{16}$ INNERARITY, op. cit., p. 114-115.

17 Sobre a "filosofia da suspeita", veja-se GENGHINI, Nevio. Verità \& consenso: la controversia sui fondamenti morali dell'ordine político. Bologna: CSEO, 1989. p. 12 e passim.
}

No âmbito ético-jurídico, isto significa, antes de mais nada, uma des-fundamentação da ordem normativa: a razão moderna, que a justificava racionalmente, desaparece e a autoridade que impunha os imperativos - no caso do imperativismo oitocentista - torna-se suspeita de encobrir um esquema de dominação ${ }^{17}$. Consequentemente, o direito fica reduzido a meras estruturas anônimas da linguagem, que ocultam e canonizam estruturas de opressão ou domínio. Kozieki escreveu que o direito reduz-se a "grafismos inventados pelo Ocidente para as suas produções de regulação social" 18 . Evidentemente, a fundamentação moderna do direito, seja racionalista ou imperativista, não é substituída por nenhuma outra; simplesmente, o direito passa a carecer de fundamento: "[H]oje em dia, o direito só pode sustentar-se na sua própria positividade" ${ }^{19}$.

b) Perda da noção de sujeito: o ataque à noção moderna de sujeito é um dos pontos centrais da crítica pós-moderna. Em Les mots et les choses, Foucault considera-a um mero "invento do século XVIII", e os autores desta corrente propõem a libertação como superação do sujeito ${ }^{20}$, isto é, substituí-lo por estruturas anônimas e inconscientes nas quais esse sujeito se desfaz até desaparecer. Neste sentido, Innerarity escreveu que o pós-estruturalismo "substitui o transcendentalismo da consciência pelo do inconsciente, sob a forma do discurso anônimo das estruturas sociais linguísticas ou simbólicas" 21. Nesta perspectiva, o sujeito não é mais o concessor de sentido da realidade; e, por outro lado, como o sentido inerente da natureza clássica não reaparece, já não há lugar onde inquirir o

18 KOZICKI, Enrique. Discurso jurídico y discurso psicoanalítico. In: AA.VV. El discurso jurídico. Buenos Aires: Hachette, 1982. p. 30.

19 EWALD, François. L'Etat providence. Paris: Grasset, 1986. p. 41.

${ }^{20}$ Cf. RENAUT; SOSOE, op. cit., p. 43 et seq.; AMATO, Salvatore. Il soggetto e il soggetto di diritto. Torino: Giappichelli, 1990. p. 31 et seq.

${ }^{21}$ INNERARITY, op. cit., p. 39. 
sentido do direito - este termina por carecer de sentido.

No campo jurídico, essa perda do sujeito significa a desaparição das noções de direito subjetivo e de direitos humanos, bem como, em suma, da própria noção de direito. De fato, o direito - e, portanto, os direitos - é uma realidade existencialmente não autônoma, que necessita de um sujeito existencialmente autônomo para existir; se excluímos esse sujeito, o direito tem de desaparecer necessariamente por carência de uma base ôntica à qual inerir para poder ser. É por isto que François Ewald, um dos tradutores da pósmodernidade no âmbito jurídico, conclui que "o direito não existe" 22 e Deleuze afirma que, "contrariamente ao que o discurso habitual sustenta, não há necessidade alguma de referir-se ao homem para resistir à dominação" ${ }^{23}$. Portanto, a resistência não é mais pensável em termos de direitos, particularmente de direitos humanos, mas em termos de relações de puro poder; assim, o mundo jurídico dissolve-se numa rede de relações meramente fáticas e sem sentido deôntico.

c) Ausência de fundamento das realidades jurídicas: por fim, em chave pós-moderna, as tentativas modernas de fundamentação do direito são questionadas e tidas como meras encobridoras de dominação. Por isto, os processos de fundamentação ou justificação racional da realidade jurídica são substituídos por uma "arqueologia" ou "genealogia" ${ }^{24}$ que procura revelar a sua origem encoberta em relações de mero poder. Em relação ao direito, Foucault levou a cabo esse processo arqueológico no seu livro $A$ verdade e as formas jurídicas; ali escreveu que:

[...] a função da análise arqueológica seria, em primeiro lugar, descobrir as continuidades obscuras

\footnotetext{
${ }^{22}$ EWALD, op. cit., p. 30.

${ }^{23}$ DELEUZE, Gilles. Foucault. Paris: Minuit, 1986. p. 98.

${ }^{24}$ Veja-se MACINTYRE, Alasdair. Tres versiones rivales de la ética: enciclopedia, genealogía y tradición. Trad. R. Rovira. Madrid: Rialp, 1992. p. 61 et seq.
}

que incorporamos e, em segundo lugar, partindo do estudo da sua formação, comprovar a utilidade que elas tiveram e ainda continuam a ter; isto é, como elas agem na atual economia das nossas condições de existência. Além disso, em terceiro lugar, a análise histórico-arqueológica permitiria determinar a qual sistema de poder essas bases ou continuidades estão ligadas e, por conseguinte, de que modo abordá-las ${ }^{25}$.

Deleuze, por sua vez, concluiu que:

[...] o direito não é senão o estado de paz resultante de uma guerra ganha; ele é a própria guerra e a estratégia dessa guerra em ato" ${ }^{26}$. Dito em outras palavras, o direito reduz-se, em última instância, a relações de puro poder ou de guerra; e a única tarefa valiosa em relação a ele é a "arqueológica", que permite descobrir a realidade originária do direito, desmascarando as tentativas de justificá-lo e, em suma, libertando-nos do passado ${ }^{27}$.

Desde logo, tanto a realidade jurídica resumida a relações de poder como a resistência a essas relações - também concebida como mera reação fática ou violenta - carecem de todo fundamento, seja transcendente ou imanente, e nem sequer o necessitam; sustentam-se por si mesmas enquanto poder fático. Assim, cabe descartar como espúrios, mistificadores ou encobridores todos os ensaios de justificação do direito.

\section{AS TENTATIVAS DE REFUNDAMENTAÇÃO (I): O NEO- ILUMINISMO}

Pois bem, é evidente que, não obstante os seus aspectos críticos positivos - os quais não cabem ser detalhados neste momento ${ }^{28}-$, o niilismo jurídico do mero poder e da desfundamentação do direito não consegue satisfazer as exigências mínimas do espírito

${ }^{25}$ FOUCAULT, Michel. La verdad y las formas jurídicas. Trad. E. Lynch. Barcelona: Gedisa, 1984. p. 171.

${ }^{26}$ DELEUZE, op. cit., p. 38.

${ }^{27}$ FOUCAULT, op. cit., p. 172.

28 Cf. VERSTRAETE, Miguel. Modernidad agónica (inédito), sobretudo o cap. V. 
humano e, consequentemente, da convivência humana social. Com efeito, para que possa existir como tal, todo sistema jurídico requer necessariamente três elementos: (1) um critério de fundamentação do direito ou da obrigatoriedade das normas jurídicas, uma vez que o mero factum da força não é suficiente para sustentar a vigência do direito; até mesmo os autores mais cruamente positivistas ${ }^{29}$ reconhecem que, para que o direito tenha uma vigência mínima, é preciso algum tipo de convencimento ético por parte daqueles que têm de respeitá-lo; (2) uma instância crítica de apelação valorativa situada para além do mero poder; a este respeito, Spaemann diz que, de fato, "os homens diferenciam ações justas de injustas. E o critério último desta diferenciação não é a adequação das ações às leis positivas existentes, pois esses mesmos homens também diferenciam leis justas de injustas, sentenças justas de injustas" 30; e (3) um subiectum [sujeito] existencialmente autônomo em que as leis e os direitos iniram ou tenham a sua existência (como já dissemos e que, ademais, é evidente); em todas as suas dimensões, o direito não tem uma existência autônoma, a qual Aristóteles chamaria acidental, de modo que necessita de um ente substantivo que sustenha a sua existência; sem essa substância, o direito não pode sequer ser pensado. Pois bem, os pensadores pós-modernos não só não proporcionam estes três elementos à teoria do direito, como também os negam explicitamente, dando lugar a outras tantas aporias, irresolúveis no âmbito desse mesmo pensamento.

A consequência dessas aporias a que o pensamento da pós-modernidade conduz inexoravelmente - sobretudo na versão do pósestruturalismo arqueológico - foi a aparição de

\footnotetext{
${ }^{29}$ Veja-se RAZ, Joseph. Ethics in the public domain. Oxford: Clarendon Press, 1994. p. 340 passim.

${ }^{30}$ SPAEMANN, op. cit., p.315.

31 Também poderiam ser feitas algumas considerações sobre os chamados comunitaristas anglo-saxônicos, mas as omitiremos por razões de espaço. Para uma visão de conjunto deste movimento, veja-se NAVAL, Concepción.
}

várias e diversas tentativas de solução ou de escape; em outras palavras, uma longa série de pensadores contemporâneos têm ensaiado várias saídas superadoras dessas dificuldades e capazes de refundamentar de algum modo o direito e os princípios da organização política, reencontrando o sujeito perdido na pós-modernidade e a necessária instância suprapositiva de apelação ética. Entre essas tentativas contemporâneas, vamos deter-nos especialmente em apenas em duas que nos parecem mais relevantes quanto a este ponto ${ }^{31}$. Após nos referirmos a elas brevemente, esboçaremos uma necessária conclusão programática.

A primeira dessas tentativas de refundamentação do direito e da política é a que se pode chamar de neoiluminismo ${ }^{32}$ ou tardomodernidade. Para esta corrente, o projeto moderno é um "projeto inacabado" (Habermas), cujos valores é preciso resgatar por intermédio de um retorno a Kant (Rawls, Renaut), aos contratualistas liberais (Nozick, Buchanan) ou à tradição utilitarista (Lyons, Scanlon). Através desse retorno à tradição moderna, tenta-se reivindicar as noções de sujeito moral ${ }^{33}$, de certos princípios de justiça não positivos e de uma fundamentação racional-construtiva desses princípios.

Nesse programa, cabe destacar principalmente a ideia de um procedimento de fundamentação dos princípios ético-jurídicos de caráter construtivo-procedimental, o que acaba sendo a acentuação de uma das características centrais do pensamento da modernidade.

Esta ideia adquire uma função paradigmática no pensamento de John Rawls. Para este autor norte-americano:

Educar ciudadanos: la polémica liberal-comutarista en educación. Pamplona: EUNSA, 1995. p. 59-126.

32 Sobre este tema, veja-se POSSENTI, Vittorio. Oltre l'illuminismo. Milano: Paoline, 1992.

${ }^{33}$ Cf. SANDEL, Michael. Liberalism and the limits of justice. Cambridge: Cambridge University Press, 1992. p. 15-65. 
[O] construtivismo kantiano defende que a objetividade moral tem de ser entendida em termos de um ponto de vista social adequadamente construído e que todos possam aceitar. Fora do procedimento de construir os princípios de justiça, não há fatos morais. Que certos atos tenham de ser reconhecidos como razões daquilo que é reto e da justiça, ou em que medida são importantes, é algo que só pode ser determinado desde dentro do procedimento de construção, ou seja, a partir dos compromissos adotados por agentes racionais de construção quando se encontram devidamente representados como pessoas livres e iguais ${ }^{34}$.

Esta pretensão de reconstruir a objetividade ética de forma procedimental não é senão uma consequência tardia do abandono moderno da lei natural; a perda da objetividade entitativa, forte, do pensamento clássico, desemboca na perda absoluta de toda objetividade - como no caso dos pós-modernos - ou na tentativa de reconstruir essa objetividade de modo formal-procedimentalconsensual. Neste último caso, chega-se a uma ética "baseada numa argumentação puramente retórica, isto é, alicerçada numa série de argumentos ad hominem, mensurada com base nas pessoas com as quais tem de ser construída" ${ }^{35}$. Mas esta ética construída procedimentalmente, sem referência alguma aos dados da experiência moral ${ }^{36}$, a princípio autoevidentes de caráter material ou de conteúdo, desemboca, por sua vez, em duas aporias fundamentais que a desautorizam enquanto alternativa válida ao niilismo pósmoderno:

a) A primeira delas é que nos encontramos diante de uma fundamentação "débil" de uma normatividade constitutivamente forte, como é a jurídica. Com efeito, a obrigatoriedade ou exigibilidade das normas ou poderes jurídicos ao menos daqueles que se mostram como centrais em todos os sistemas de direito - só pode ser

\footnotetext{
${ }^{34}$ RAWLS, John. Justicia como equidad. Trad. M. A. Rodilla. Madrid: Tecnos, 1986. p. 140.

35 VATTIMO, Gianni. La filosofia al presente. Milano: Garzanti, 1990. p. 86.
}

pensada na medida em que exige um respeito incondicional, absoluto ou sem exceção; uma obrigação que possa ser "superada" ou deixada de lado por causa de considerações de utilidade pessoal ou coletiva, de conveniência subjetiva ou de fastio pessoal, não pode ser considerada rigorosamente como jurídica. A necessidade deôntica é uma das características imprescindíveis da juridicidade, ao menos no seu núcleo central e no seu significado mais próprio, e é evidente que a fundamentação procedimentalconstrutiva não atinge a "força" necessária para justificá-la racionalmente.

b) A segunda das aporias do construtivismo procedimental-consensual reside naquilo que chamamos de "falácia procedimentalista", que consiste na pretensão de obter princípios éticojurídicos de conteúdo a partir do mero procedimento argumentativo da razão prática construtiva. Num dos seus últimos trabalhos, Arthur Kaufmann pôs em evidência como é impossível extrair conclusões materiais ou de conteúdo sem que se incluam no raciocínio conteúdos provenientes em alguma medida da experiência ${ }^{37}$. Por outro lado, esta é uma exigência ineludível da lógica, que impede que apareça nas conclusões de um raciocínio algo não contido de algum modo nas premissas antecedentes. Deste modo, se aquilo que é posto nas premissas do raciocínio procedimentalista são meras construções formais (situações originais, véus de ignorância, libertações de domínio etc.), só haverá na conclusão - por mais voltas que se deem aos argumentos - um conjunto de proposições sem conteúdo material e que se referem às meras formas do raciocínio.

36 Acerca da noção de experiência moral, veja-se PRIVITERA, Salvatore. Dall'esperienza alla morale. Palermo: OFTES, 1985.

${ }^{37}$ Cf. KAUFMANN, Arthur. La filosofía del derecho en la posmodernidad. Trad. L. Villar Borda. Bogotá: Temis, 1992. p. 47 et seq. 
5

REFUNDAMENTAÇÃO

Porém bem claro está que não é esta ética débil e meramente formal que pode superar as aporias propostas tão agudamente pela pósmodernidade jurídica. $\mathrm{Na}$ verdade, esta saída neoiluminista não é uma saída, mas antes uma recaída agravada nas perplexidades e dificuldades irresolúveis do pensamento moderno. Por isto, é preciso dirigir o olhar a outra tentativa de superação do niilismo irracionalista, que, ao mesmo tempo, também é uma tentativa de superação do racionalismo construtivista e do positivismo típicos da mentalidade moderna. Trata-se da mais recente renovação do pensamento jusnaturalista. Nessa renovação, o que se tenta, antes de mais nada, é a reformulação de um objetivismo ético-jurídico que tenha como base a verdade; para tanto, é imprescindível abrirse novamente à natureza das coisas humanas. Essa abertura - sobretudo no âmbito de sociedades multiculturais - deve ser feita por meio de um diálogo que seja o mais amplo possível, mas que tem de ser um "diálogo veritativo" 38 , isto é, estruturado sobre a pressuposição de que é possível alcançar a verdade no âmbito da práxis humana. Além disso, essa verdade não pode ser alcançada sem um necessário recurso à experiência, sensível e espiritual, das realidades própria e especificamente humanas.

Em segundo lugar, apenas sobre esta base é possível alcançar uma fundamentação "forte" do direito e das instituições políticas; uma justificação racional da regulação da práxis humana que atinja o grau de nãoexcepcionalidade que essa regulação requer. Para isto, também é necessário arraigar a realidade jurídica num sujeito existencialmente autônomo, o qual terá de possuir o caráter de pessoa, em
E virtude da sua racionalidade e da sua liberdade.

O Pessoa que não se confunde com o sujeito autossuficiente, construtor e único doador de sentido - típico do pensamento moderno -, mas, sim, uma substância racional constitutivamente aberta à "coexistência ontológica" (Sergio Cotta) com os seus semelhantes e ordenada a uma perfeição, por meio da qual ela é participante de um bem humano comum.

Para a realização desta tarefa, é mais que conveniente recorrer à milenária tradição da doutrina da lei natural. Mas, hoje em dia, é indubitável que não basta remeter-se aos aportes de uma tradição para tornar novamente aceitável a ideia da existência de algo intrinsecamente justo; uma nova época requer uma nova versão do direito natural. Isto não significa sustentar que deva tratar-se de uma versão completamente nova, mas de que tem de ser formulada a partir dos novos dados oferecidos pela experiência da vida social atual; por exemplo, das exigências que se seguem da crise ecológica atual e das propostas morais e jurídicas geradas pela biologia e pela medicina contemporâneas. E não se tem de ter em conta apenas as novas experiências, mas também as colaborações mais recentes efetuadas no campo da filosofia e da metodologia, tais como a hermenêutica, a metateoria contemporânea da ciência e a filosofia analítica, convenientemente criticadas nos seus reducionismos, nas suas contradições e nas suas consequências indesejadas.

Obviamente, esta tarefa não é das mais fáceis; é muito mais cômodo remeter-se dogmaticamente a textos veneráveis, interpretados segundo chaves hermenêuticas também veneráveis. O problema é que a versão do direito natural resultante disto é pouco compreensível - ou até mesmo incompreensível para as pessoas de hoje. Assim, essas doutrinas do direito natural, mantidas inabaláveis e

${ }^{38}$ CHALMETA OLASO, Gabriel. Ética especial: el orden ideal de la vida buena. Pamplona: EUNSA, 1996. p. 202. 
imodificáveis ao longo dos séculos, não podem cumprir a função crítica e de justificação racional que os tempos atuais - assim como todos os tempos - requerem delas. Portanto, é preferível correr o risco de repensar - sempre com a ajuda da tradição jusnaturalista - os problemas que a vida social contemporânea - o da justiça, em especial - apresentam agudamente ao espírito humano e resolvê-los a partir de uma perspectiva dialógica, mas veritativa; plural, mas não relativista; racional, mas não sistemista; universalista, mas aberta à diversidade das concreções prudenciais dos princípios do direito natural. Pode-se alegar que esta tarefa é árdua, complexa e arriscada, mas também é verdade que não existe nem existiu aventura humana que não possua estas características. E esta, em particular, vale a pena ser assumida com decisão e grandeza de espírito.

Por fim, e antes de esboçarmos as conclusões cabíveis, resumiremos esquematicamente num quadro o que se sustentou até aqui. O quadro é este:

\begin{tabular}{|c|c|c|c|}
\hline $\begin{array}{c}\text { PENSAMENTO } \\
\text { MODERNO }\end{array}$ & $\begin{array}{c}\text { FILOSOFIA } \\
\text { JURÍDICA } \\
\text { MODERNA }\end{array}$ & $\begin{array}{c}\text { REAÇÃO PÓS- } \\
\text { MODERNA }\end{array}$ & $\begin{array}{c}\text { TENTATIVAS } \\
\text { DE SUPERAÇÃO }\end{array}$ \\
\hline $\begin{array}{c}\text { Perda da noção } \\
\text { teleológica-normativa } \\
\text { de natureza }\end{array}$ & $\begin{array}{c}\text { Perda da noção de lei } \\
\text { natural - razão } \\
\text { construtiva }\end{array}$ & $\begin{array}{c}\text { Crítica da razão } \\
\text { sistemática ("grandes } \\
\text { relatos") }\end{array}$ & \multirow{2}{*}{$\begin{array}{c}\text { Neoiluminismo } \\
\text { procedimental- } \\
\text { consensual }\end{array}$} \\
\cline { 1 - 3 } $\begin{array}{c}\text { Sujeito configurador e } \\
\text { doador de sentido dos } \\
\text { seus objetos }\end{array}$ & $\begin{array}{c}\text { Aparição da noção } \\
\text { moderna de direitos } \\
\text { humanos }\end{array}$ & $\begin{array}{c}\text { Crítica da noção de } \\
\text { sujeito: estruturas } \\
\text { anônimas inconscientes }\end{array}$ & ---------- \\
\cline { 1 - 2 } $\begin{array}{c}\text { Imanentização } \\
\text { progressiva do } \\
\text { pensamento e da vida }\end{array}$ & $\begin{array}{c}\text { Fundamentação } \\
\text { imanente do direito: } \\
\text { racional-imperativista }\end{array}$ & $\begin{array}{c}\text { Crítica da fundamentação } \\
\text { moderna do direito: } \\
\text { somente arqueologia do } \\
\text { saber-poder }\end{array}$ & $\begin{array}{c}\text { Renascimento das } \\
\text { teorias } \\
\text { jusnaturalistas }\end{array}$ \\
\cline { 1 - 2 }
\end{tabular}

\section{CONCLUSÃO}

De todos os desenvolvimentos realizados, é possível extrair duas conclusões principais para a problemática que nos ocupa, que resumiremos do seguinte modo:

a) Nos tempos pós-modernos, a teoria do direito natural encontra-se numa situação paradoxal: por um lado, mostra-se como a saída necessária do atomismo niilista e desfundamentador do crepúsculo da modernidade; mas, por outro lado, depara com graves dificuldades de formulação e de comunicação ao homem contemporâneo. Com efeito, o homem dos nossos dias não compartilha as certezas e imagens que eram compartilhadas por aqueles que, antes da Idade moderna, formularam as doutrinas clássicas do direito natural; em outras palavras, já não é possível tomar como óbvia toda uma série de pressupostos nocionais: a concepção teleológica da natureza, o sujeito como substância racional, o caráter transcendente do fundamento da ética etc. Portanto, atualmente, a tentativa de refundamentar o direito a partir das estruturas da realidade tem de lidar com numerosos desafios; o primeiro é iniciar esta tarefa desde muito mais "atrás" - ou desde muito mais "profundo" - e com muitos menos pressupostos em comparação com a quantidade de pressupostos da maioria das formulações anteriores, inclusive algumas realizadas quando o século XX já estava bem avançado. 
b) Apesar destas dificuldades de constituição e formulação, a teoria do direito natural tem algumas funções insubstituíveis a ser cumpridas neste tempo de fim e ocaso da modernidade ${ }^{39}$. Antes de mais nada, essas funções são a de procurar a necessária fundamentação "forte" das realidades jurídicas, isto é, a de fornecer uma justificação racional das suas obrigatoriedade e exigibilidade, de modo que seja proporcional ao caráter inescusável ou absoluto - em sentido deôntico - dos imperativos, deveres e poderes jurídicos. Em segundo lugar mas, a rigor, de maior importância -, é função inescusável do direito natural de afirmar e assegurar a indisponibilidade do direito:

Com o nascimento da ciência moderna, produziu-se o abandono da teleologia. Esse abandono não foi forçado pelo fenômeno; por trás dele, escondia-se um interesse poderoso. $\mathrm{O}$ fenômeno até mesmo se opõe a uma interpretação não teleológica. Por isto, força um equivalente provisório. Um desses equivalentes é a doutrina dos dois mundos, em suas diferentes formas: reino das causas e reino dos fins, ser e dever, fatos e valores. A própria teoria dos valores é um desses equivalentes. Fatos desprovidos de valor e reino de valores oposto a esses fatos são o produto da desintegração da enteléquia [a natureza como fim] precedente ${ }^{40}$.

Pois bem, como estas funções são absolutamente necessárias, dado o caráter das realidades jurídicas, também é necessário abordar a tarefa de reformulação da teoria do direito natural. Esta tarefa tem de ser realizada encarando e superando as dificuldades que o nosso tempo lhe apresenta, mas sem amedrontamento ou defecção perante a complexidade e multiplicidade delas. Essas dificuldades têm de ser, em vez de obstáculos, novos desafios às inteligências abertas e comprometidas com a defesa do núcleo de humanidade que jamais pode faltar no direito.

\section{REFERÊNCIAS}

ALVIRA, Rafael. Reivindicación de la voluntad. Pamplona: EUNSA, 1988.

AMATO, Salvatore. Il soggetto e il soggetto di diritto. Torino: Giappichelli, 1990.

BALLESTEROS, Jesús. Posmodernidad: decadência o resistencia. Madrid: Tecnos, 1989.

BARRET-KRIEGEL, Blandine. Les droits de l'homme et le droit naturel. Paris: PUF, 1989.

CARPINTERO, Francisco. Los inicios del positivismo jurídico en Centro Europa. Madrid: Actas, 1992.

CHALMETA OLASO, Gabriel. Ética especial: el orden ideal de la vida buena. Pamplona: EUNSA, 1996.

DELEUZE, Gilles. Foucault. Paris: Minuit, 1986.

\footnotetext{
39 Neste ponto, cabe recordar o valioso livro de GUARDINI, Romano. El fin de los tiempos modernos. Buenos Aires: Sur, 1958 (o original alemão é de 1950), em que se apresenta o problema do ocaso da modernidade vários anos antes da aparição da literatura pós-moderna.
}

${ }^{40}$ SPAEMANN, Robert. La actualidad del derecho natural. In: SPAEMANN. Crítica de las utopías políticas. Pamplona: EUNSA, 1980. p. 324-325. Sobre as ideias de Spaemann a este respeito, veja-se GONZÁLEZ, Ana Marta. Naturaleza y dignidad: un estudio desde Robert Spaemann. Pamplona: EUNSA, 1996. 
ELLSCHEID, Günter. El problema del derecho natural. Una orientación sistemática. In: ROBLES, Gregorio (ed.). El pensamiento jurídico contemporáneo. Barcelona: Debate, 1992.

EWALD, François. L'Etat providence. Paris: Grasset, 1986.

FAZIO, Mariano; GAMARRA, Daniel. Introduzione alla storia della filosofia moderna. Roma: Apollinare Studi, 1994.

FOUCAULT, Michel. La verdad y las formas jurídicas. Trad. E. Lynch. Barcelona: Gedisa, 1984.

GENGHINI, Nevio. Verità \& consenso: la controversia sui fondamenti morali dell'ordine político. Bologna: CSEO, 1989.

GÓMEZ ROBLEDO, Antonio. Ensayo sobre las virtudes intelectuales. México: Fondo de Cultura Económica, 1986.

. L'etica teologica e le istanze della posmodernità. In: AA.VV. Prospettive etiche nella posmodernità. Milano: San Paolo, 1994.

GONZÁLEZ, Ana Marta. Naturaleza y dignidad: un estudio desde Robert Spaemann. Pamplona: EUNSA, 1996.

GOYARD-FABRE, Simone. Les fondements de l'ordre juridique. Paris: PUF, 1992.

GUARDINI, Romano. El fin de los tiempos modernos. Buenos Aires: Sur, 1958.

HAAKONSEN, Knud. Natural law and moral philosophy: from Grotius to the Scottish enlightenment. New York: Cambridge University Press, 1996.

HABERMAS, Jürgen. El discurso filosófico de la modernidad. Buenos Aires: Taurus.

HUME, David. Treatise of human nature. London: Penguin Classics, 1985.

INNERARITY, Daniel. Dialéctica de la modernidad. Madrid: Rialp, 1990.

KAUFMANN, Arthur. La filosofía del derecho en la posmodernidad. Trad. L. Villar Borda. Bogotá: Temis, 1992.

KELLY, John M. A short history of Western legal theory. Oxford: Clarendon Press, 1994.

KOZICKI, Enrique. Discurso jurídico y discurso psicoanalítico. In: AA.VV. El discurso jurídico. Buenos Aires: Hachette, 1982.

LLANO, Alejandro. Claves filosóficas del actual debate cultural. Humanitas, Santiago de Chile, 1996, n. 4 , p. 532-544.

MACINTYRE, Alasdair. Tres versiones rivales de la ética: enciclopedia, genealogía y tradición. Trad. R. Rovira. Madrid: Rialp, 1992. 
MASSINI CORREAS, Carlos Ignacio. La desintegración del pensar jurídico clásico en Edad Moderna. Buenos Aires: Abeledo Perrot, 1980.

NAVAL, Concepción. Educar ciudadanos: la polémica liberal-comutarista en educación. Pamplona: EUNSA, 1995.

POSSENTI, Vittorio. Oltre l'illuminismo. Milano: Paoline, 1992.

PRIVITERA, Salvatore. Dall'esperienza alla morale. Palermo: OFTES, 1985.

RAWLS, John. Justicia como equidad. Trad. M. A. Rodilla. Madrid: Tecnos, 1986.

RAZ, Joseph. Ethics in the public domain. Oxford: Clarendon Press, 1994.

RENAUT, Alain; SOSOE, Lukas. Philosophie du droit. Paris: PUF, 1993.

ROSEN, Allen D. Kant's theory of justice. Ithaca; London: Cornell University Press, 1993.

SANDEL, Michael. Liberalism and the limits of justice. Cambridge: Cambridge University Press, 1992.

SPAEMANN, Robert. La actualidad del derecho natural. In: IDEM. Crítica de las utopías políticas. Pamplona: EUNSA, 1980.

TOMÁS DE AQUINO. Suma de teologia.

VATTIMO, Gianni. La filosofia al presente. Milano: Garzanti, 1990.

VERSTRAETE, Miguel. Modernidad agónica (inédito).

VILLEY, Michel. La formation de la pensée juridique moderne. Paris: Montchrestien, 1968.

Recebido em: 23/12/2018

Aceito em: 23/12/2018 
